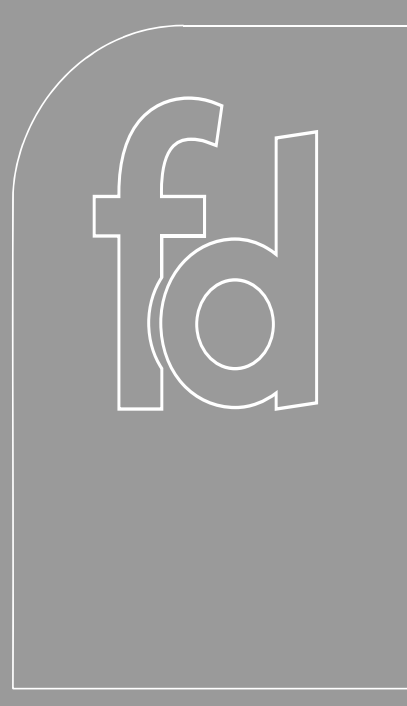

CONTENTS

Multiple facets of metabolic syndrome

Complex milieu of the white adipose tissue: secretion of pro-inflammatory adipokines \& cytokines

Adipokines

Melanocortins

Expert commentary $\&$ five-yearview

Key issues

References

Affiliations

\footnotetext{
${ }^{\dagger}$ Author for correspondence Inova Fairfax H ospital, Center for Liver Diseases, D epartment of M edicine, 3300 Gallows Road, Falls Church, VA22042, USA

Tel.: +1 703698 3182; $+17032086650$

Fax: +1 703698 3482; +17032086655 zobair.younossi@inova.com

KEYWORDS:

adiponectin, $\alpha-\mathrm{M} \mathrm{SH}$, insulin resistance, leptin, metabolic syndrome, nonalcoholic fatty liver disease, nonal coholic steatohepatitis, T N F- $\alpha$, visceral adipose
}

\title{
Adipokines and melanocortins in the hepatic manifestation of metabolic syndrome: nonalcoholic fatty liver disease
}

\author{
Ancha Baranova, Manpreet Randhawa, M ohammed Jarrar \\ and Zobair M Younossi ${ }^{\dagger}$
}

Metabolic syndrome is associated with nonalcoholic fatty liver disease and its more aggressive form, nonalcoholic steatohepatitis. Adipokines produced by white adipose tissue possess broad physiological activity and play an important autocrine role in obesity-associated complications, including metabolic syndrome, nonalcoholic fatty liver disease and cardiovascular disease. Various adipokines may have beneficial or hamful effects. Other tissues, particularly stomach and intestine, produce active molecules that can influence the function of adipocytes and, possibly, the levels of adipokine secretion. In some cases, the production sites of these molecules remain unknown. The review foc uses on our cument understanding of the disease-related effects of the adipokines and the melanocortins on various peripheral tissues, and disc usses some of their potential interactions with each other. Potential therapeutic applications are also considered.

Expert Rev. M ol. Diagn. 7(2), 195-205 (2007)

\section{Multiple facets of metabolic syndrome}

M etabolic syndrome (M S) was first introduced as a clinical entity by Reaven in 1988 [1]. M S represents a cluster of risk factors commonly associated with central obesity, insulin-resistance, hypertension and elevated triglycerides, as well as decreased high-density lipoprotein cholesterol. In turn, MS is associated with an increased risk of cardiovascular disease and is a common early abnormality in the development of Type 2 diabetes. Additionally, MS plays a well-recognized role in the development of the obstructive sleep apnea, erectile dysfunction, polycystic ovary syndrome and malignant tumors. It is noteworthy that, despite tremendous clinical impact of MS, there is no clear consensus regarding the diagnostic criteria for this important nosological entity. To date, different criteria have been proposed by the $\mathrm{WHO}$, by the third report of the National Cholesterol Education Program Adult Treatment Panel III (AT PIII) on D etection, Evaluation, and Treatment of $\mathrm{H}$ igh
Blood Cholesterol in Adults, International Diabetes Federation, European Group for the Study of Insulin Resistance, and American College of Endocrinology. The problem of multiple MS definitions was recently addressed in a joint statement of The American Diabetes Association and the European Association for the Study of D iabetes [2]. The statement and other publications stress the necessity of introduction of additional criteria for MS including concentrations of the proand anti-inflammatory proteins in the serum. It is most likely that the list of the etiological factors driving the development of MS includes abnormalities in visceral adipose tissue or an altered inflammatory background that, in turn, stimulate the development of the secondary complications of M S.

Recently, nonalcoholic fatty liver disease (N AFLD) and its more aggressive form, nonalcoholic steatohepatitis (N ASH), have come to be regarded as the hepatic manifestation of MS. In this context, insulin resistance (IR) is 
the key event linking N AFLD to the M S [3]. The epidemiology, pathogenesis and approach to treatment of NAFLD follow the same trends as all other metabolic disorders [4,5]. N AFLD represents a spectrum of clinicopathologic disorders. At one end of the N AFLD spectrum is simple steatosis, and at the other end is N ASH , characterized by hepatic steatosis, hepatocyte ballooning degeneration, lobular inflammation with or without $\mathrm{M}$ allory hyalines, or sinusoidal fibrosis [6]. To date, no treatment has been proven effective for NASH. Treatment strategies mostly pursue modification of underlying metabolic abnormalities such as Type 2 diabetes mellitus, hyperlipidemia and obesity [7].

The pathogenesis of N ASH is multifactorial and is the subject of intense research. Potential theories include influences of the abnormalities of lipid metabolism and the production of reactive oxygen species, leading to increased hepatic lipid peroxidation, activated fibrocytes and abnormal patterns of cytokine production. These events can lead to multiple hits responsible for NASH -related liver cell injury and fibrosis [3]. In the multihit hypothesis of N ASH , the first hit appears to be the accumulation of excessive fat in the hepatic parenchyma $[7,8]$. This first hit has been linked to IR, which has been consistently observed in patients with N ASH [3]. The second hit involves oxidative stress, resulting from an imbalance between pro- and antioxidant processes [3,8]. Both the first and the second hits, which are considered important for development of N AFLD and its progression, are dependent on local and circulating levels of various pro- and anti-inflammatory cytokines, including adipokines.

\section{Complex milieu of the white adipose tissue: secretion of proinflammatory adipokines \& cytokines}

White adipose tissue (WAT) is increasingly recognized as an endocrine organ producing numerous proteins collectively referred to as adipokines. A partial list of these proteins

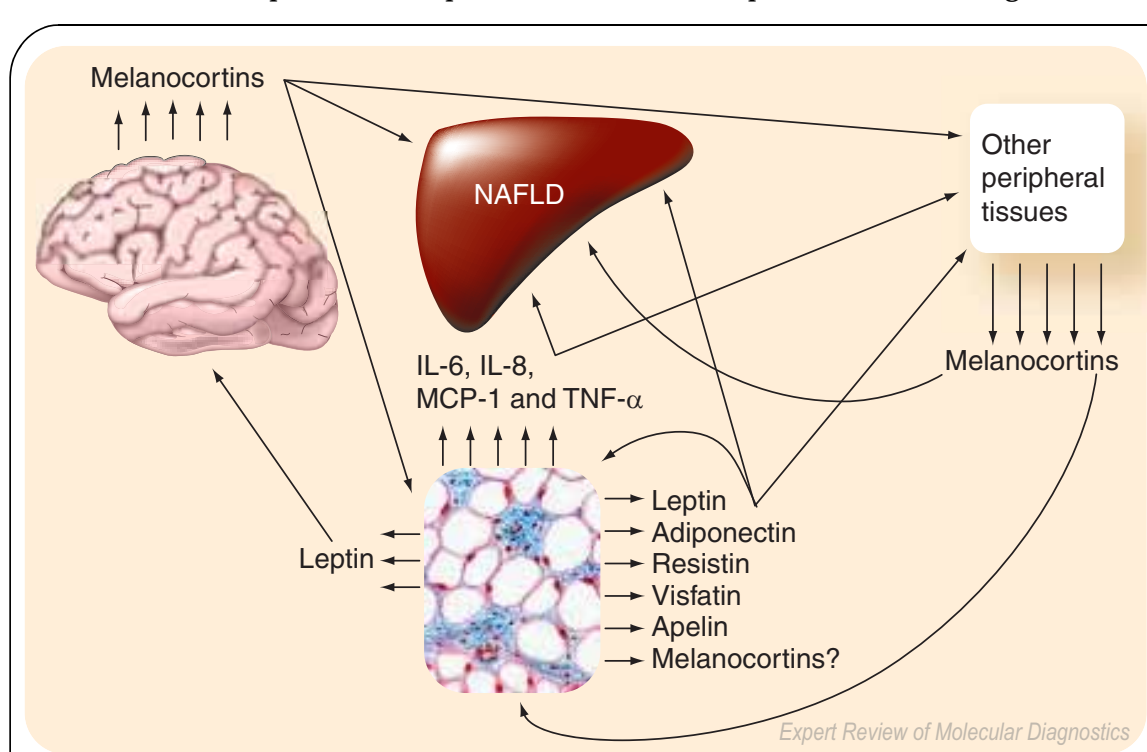

Figure 1. Complexity of intreplay between cytokines and adipokines possibly involved in the development of insulin resistance, NAFLD and nonalcoholic steatohepatitis.

IL: Interleukin; MCP: Monocyte chemoattractant protein; NAFLD: Nonalcoholic fatty liver disease; TNF: Tumor necrosis factor. includes: adiponectin, resistin, leptin, visfatin, apelin, vaspin and other bioactive molecules. These proteins possess broad physiological activity and play an important autocrine role in obesity-associated complications, including MS, N AFLD and cardiovascular diseases [9].

In addition to adipokines in a sensu stricto, adipose tissue produces a number of traditional cytokines, such as tumor-necrosis factor (TN F)- $\alpha$, monocyte chemoattractant protein (M CP) 1 and interleukin (IL)-6, thus adding pro-inflammatory pressure to other peripheral tissues of the human body. These traditional cytokines are mostly produced by macrophages embedded in the adipose stroma [10]. In addition to the elevation of the traditional cytokines, excessive adipose tissue also produces abnormal amounts of adipokines. In general, adipokines modulate many physiological processes, including energy homeostasis, lipid metabolism, blood-pressure regulation, insulin sensitivity and angiogenesis [11]. O ne example of the adipocyte cross-talk with other peripheral tissues has been discovered in the co-culture experiments of human fat and skeletal muscle cells [12]. It is now clear that the imbalance in the synthesis and secretion of adipokines negatively impacts skeletal muscles and promotes the vicious cycle of IR [13,14].

Systematic studies of cytokine and adipokine levels in patients with chronic diseases usually evaluate protein content in serum samples reflecting the total volume of the production of a particular molecule by all the tissues. Even the classical adipokines, including resistin and adiponectin, could be produced somewhere else in the body in addition to adipose depots, as was demonstrated both at the protein and mRNA level. Nevertheless, WAT remains the most important source of these molecules, especially in obese individuals. A net elevation in the WAT secretion of pro-inflammatory molecules comes from multiple sources, including overall increases in body fat volume and an increase in the number of infiltrating macrophages per gram of fat that parallels increase in the fat mass during the progression of obesity $[10,15]$. Visceral adipose tissue releases more IL-6, transforming growth factor (TGF)- $\beta$, IL-8, IL-10 and some other cytokines per gram of tissue than abdominal subcutane ous adipose tissue [10]. Therefore, preferential accumulation of the visceral adipose in the central obesity of patients with so-called apple-shaped obesity provides the inflammatory background that predisposes these patients to the development of the M S and its complications.

It is important to emphasize that different adipokines may have beneficial or harmful effects. Furthermore, these effects can be tissue specific, leading to the development of a particular complication of obesity. Some adipokines contribute to the pro-inflammatory effects of the adipose accumulation, whereas others counteract 
IR or alleviate hepatic steatosis and fibrosis. However, specific signaling pathways evoked by adipokine binding to their specific receptors and subsequent molecular consequences of this binding are unknown in most cases. In addition to their paracrine effects in the distant peripheral tissues, adipokines could signal locally through receptors displayed at the membranes of the adjacent adipocytes. These signaling events may reciprocally modulate production of other adipokines and cytokines or cross-talk with other molecular cascades (FIGURE 1). In addition, other tissues, particularly stomach and intestine, produce active molecules that can influence the function of adipocytes and, possibly, the levels of adipokine secretion [16]. In some cases, the production sites of these molecules remain unknown. For example, melanocortins previously implicated in energy homeostasis in the hypothalamus circulate in the blood and exert numerous peripheral effects.

The remainder of this review focuses on our current understanding of the disease-related effects of the adipokines and the melanocortins on various peripheral tissues, and describes some of their potential interactions. Therapeutic implications are also discussed.

\section{Adipokines \\ Adiponectin}

Adiponectin, which is also known as AdipoQ and Acrp30 possesses structural homology to collagens and to complement factor $\mathrm{Clq}$, and is downregulated in obese individuals. $\mathrm{M}$ any experimental studies have suggested that adiponectin plays a protective role in the development of IR, atherosclerosis and other inflammatory processes [17]. There is the possibility of some direct link between insulin and adiponectin signaling, as adiponectin stimulates the interaction between a small GT Pase Rab5 and amyloid precursor protein-like protein (APPL)1, leading to increased glucose transporter (GLUT)4 membrane translocation [18]. $O$ ther pharmacological effects of adiponectin in reducing IR are related to a decrease in plasma fatty acid levels and in triglyceride content in muscle and liver, possibly by induction of acyl-C OA oxidase and uncoupling protein-2 [19]. Adiponectin activates adenosine monophosphate-activated protein kinase (AM PK) $\alpha 1$ and - $\alpha 2$ by increasing Thr172 phosphorylation, an effect associated with increased acetyl-coenzyme A carboxylase (ACC)- $\beta$, Ser221 phosphorylation and enhanced rates of fatty acid oxidation [20]. Adiponectin-associated AM PK activation may result in a net decrease in hepatocyte triglyceride storage either by inhibiting genes required for de novo free fatty acid synthesis, or by increasing the activity of peroxisome proliferator-activated receptors (PPARs) resulting in increased $\beta$-oxidation of free fatty acids. In addition, adiponectin regulates energy balance at the mitochondrial level through augmentation of the mitochondrial biogenesis, palmitate oxidation and citrate synthase activity, and the decrease of the reactive oxygen species levels [21]. Adiponectin also inhibits hypertrophic signaling in the myocardium, thus exerting beneficial actions on the heart after pressure overload and ischemia-reperfusion injury [22], as well as preventing vascular inflammation through selective increase of the tissue inhibitor of metalloproteinase (TIM P)-1 expression in human macrophages. IR-related peripheral effects of adiponectin are summarized in FIGURE 2.

The autocrine signaling mechanisms of adiponectin that act upon neighboring adipocytes are more poorly understood than its paracrine effects. In WAT, adiponectin acts as a key regulator of adipocyte secretory function [23] and differentiation [24]. In particular, adiponectin reduces the release of fat cell secretory products, including IL-6, IL-8, growth-regulated oncogene (GRO )- $\alpha$, M CP-1, macrophage inflammatory protein (M IP)-1 $\alpha$ and $-1 \beta$, as well as TIM P-1 and -2 [23]. This function of adiponectin is consistent with the hypothesis that its obesity-related decrease profoundly perturbs the entire adipokine and cytokine milieu of the human body, providing a pro-inflammatory background that predisposes individuals to various comorbidities. Both adiponectin receptor (AdipoR)1 and 2 are expressed in adipocytes. AdipoR 1 expression in adipose tissue is reduced in obese individuals and is increased after weight loss [25]. This may lead to a reduction in the biological function of the adiponectin in WAT, further aggravating the negative metabolic effect of low adiponectin levels.

Accumulating evidence suggests that hypoadiponectinemia may predispose morbidly obese patients to the secondary cardiovascular and hepatic complications. Plasma adiponectin levels 
are significantly lower in NAFLD patients than in their matched controls [26,27]. This is also true for the patients with coronary artery disease [28]. M oreover, researchers report a similar relationship between low adiponectin production and other obesity-associated morbidities, including major depression [29], decreased ovarian function [30] and endometrial cancer [31]. These observations suggest that hypoadiponectinemia may be responsible for obesity-related health deterioration rather than being the molecular trigger for particular complications of M S.

The role of adiponectin in the pathogenesis of NAFLD and NASH is under investigation. D espite its clear involvement in N AFLD, adiponectin alone does not clearly distinguish patients with N ASH from those whose liver biopsies demonstrate simple steatosis [27]. O ne study demonstrated that reductions in the levels of circulating adiponectin in NAFLD are related to hepatic insulin sensitivity and the amount of hepatic fat, but not to the severity of necroinflammation and fibrosis [32]. In contrast, some studies have reported that hypoadiponectinemia is associated with hepatic necroinflammation and fibrosis, independent of IR [33,34]. Lower levels of adiponectin in patients with N ASH compared with those with simple steatosis, are accompanied by a decrease in AdipoR2 mRNA expression in NASH livers [35]. However, this correlation between adiponectin and AdipoR2 reduction is not uniform across the cell types, which is indicative of the complex regulation of adiponectin signaling within the liver [35].

In summary, despite the recent excitement about the role of adiponectin in the pathogenesis of M S-related complications (e.g., coronary artery disease [CAD ], IR and N AFLD) and its potential therapeutic roles, additional studies are needed to further elucidate and clarify this potential role.

\section{Leptin}

Leptin released by human adipocytes negatively regulates food intake and fatty acid metabolism through its actions on specific hypothalamic nuclei. Recent work shows that receptors to leptin, encoded by the gene LEPR, are expressed both centrally and peripherally. $\mathrm{H}$ igh mRN A levels of both short and long leptin receptor (LEPR) isoforms have been identified in the stomach, intestine, liver and pancreas [36].

Whether serum leptin elevation contributes a metabolic effect to the development of N AFLD is unclear. Higher than normal leptin concentrations are found in various types of NAFLD, including N ASH [37,38]. O bservations on serum leptin concentrations in 122 Japanese workers indicated a correlation with serum activity of alanine aminotransferase (ALT) [39]. Because patients with hepatic viral infection, autoimmune liver diseases, liver cirrhosis and drinking problems were excluded from this study, the NAFLD type of the metabolic disorders was expected to be a major cause of increased transaminase levels in the studied cohort. The absence of significant associations between ethanol consumption or lifestyle parameters and serum leptin levels support the assumption that leptin directly promotes fat accumulation in the liver [39].
Leptin can contribute to the development of the NASH in two ways. First, a dysfunctional leptin system promotes IR and alters insulin signaling in hepatocytes to increase fatty acids influx and induce lipotoxicity. Recent experiments modulating hepatic triglyceride (TG) stores in a genetically leptin-resistant rat with removed WAT confirmed that resistance to leptin is the major physiological mechanism for hepatic steatosis [41]. This view is also supported by the observation that leptin levels correlate directly with the severity of hepatic steatosis, but not with inflammation or fibrosis [42].

Also, in a later stage, leptin may contribute to the progression of steatosis to steatohepatitis by enhancing the systemic lowgrade inflammation that could be evaluated by monitoring the serum concentrations of C-reactive protein [43]. In particular, activation of the LEPR in hepatic stellate cells leads to increased expression of proinflammatory cytokine M CP-1 and proangiogenic vascular endothelial growth factor (VEGF) and angiopoietin-1 [44]. It was also postulated that leptin acts as a profibrogenic cytokine in sinusoidal microenvironment by acting both on endothelial cells and Kupffer cells [45], as it participates in the development of the liver fibrosis associated with chronic viral infections and with primary biliary cirrhosis [46].

The involvement of the leptin in the development of the fibrosis in NAFLD is less obvious; a longitudinal study of NAFLD patients revealed no differences in leptin levels in patients with fibrosis progression and those who did not progress [47]. On the other hand, an increase in expression was found both for LEPR mRNA and its protein in patients with N ASH , especially those with fibrosis [48]. There was a strong correlation between the expression of the LEPR and profibrogenic factor T G F- $\beta$ [48]. It is possible that leptin directly stimulates TFG - $\beta$ production in the liver, as it does in peritoneal mesothelial cells [49]. Another mechanism of the fibrogenic action of the leptin is its direct stimulation of Collagen I and III mRNA transcription, which is pronounced at concentrations observed in obesity $(30-50 \mathrm{ng} / \mathrm{ml})$, but not concentrations observed in nonobese individuals $(<10 \mathrm{ng} / \mathrm{ml})$ [50].

\section{Resistin \& resistin-like molecules}

Resistin and resistin-like molecules (RELM ) comprise a family of proteins related to $I R$ and inflammation. Resistin, also known as FIZZ3, is increasingly recognized as a factor that directly causes IR in animal models [51]. Treatment of skeletal muscle cells with recombinant resistin reduces the function of insulin receptor substrate (IRS)-1 and serine/threonine kinase Akt1 and decreases the translocation of GLUT 4 and glucose uptake in response to insulin [52]. Resistin also decreases fatty acid oxidation in skeletal muscle while increasing intracellular lipid accumulation [52].

Resistin plays several roles in adipose tissue. In 3T 3-L1 adipocytes, resistin impairs insulin action at multiple steps in the signaling cascade, leading to GLUT 4 inhibition and the reduction of the glucose uptake by $30 \%$ [53]. Recent findings also suggest that resistin inhibits adipocyte differentiation [53]. D ifferentiated 3T 3-L1 adipocytes that overexpress resistin produce 
much larger quantities of the proinflammatory cytokines, particularly TN F $\alpha$, IL- 6 and M CP-1, which play important roles in IR and in glucose and lipid metabolism during adipogenesis [53]. Resistin may also influence the proliferation of muscle cells and the fibrotic process. The introduction of RELM - $\alpha$ (a homologue of the resistin) into fibroblasts boosts the deposition of collagen and stimulates myofibroblast differentiation [54]. RELM - $\alpha$ al so possesses angiogenic and vasoconstrictive properties that exceed those of endothelin-1 or angiotensin II [55], and plays a role in bone metabolism [56].

It should be noted that these findings are based on mouse models and rodent cell lines, and that human resistin signaling may be different (there are substantial differences in the resistin encoding genes in rodents and humans). For example, resistin mRNA expression levels in adipose tissue and serum levels of resistin are extremely low in humans (one of 250 of that seen in the mouse). The spectrum of RELM $s$ in humans and mice are also different. In fact, the resistin- $\alpha$-encoding gene is absent in humans. These differences suggest that the family of resistinencoding genes is not been well conserved in evolution and it functions differently in different species [57]. For example, adipocytes treated with human resistin demonstrate an intact insulin response [58]. Together, these findings suggest that researchers should exercise caution when interpreting resistin-related results obtained in rodent models and generalizing to humans.

Clinical studies using enzyme-linked immunosorbent assay (ELISA)-based measurements of resistin point to its potential role in the pathogenesis of obesity-mediated IR and Type 2 diabetes mellitus [59]. H owever, other clinical studies have failed to establish a direct connection between resistin, IR and obesity $[60,61]$. The role of resistin in the pathogenesis of NAFLD is under investigation. Due to its pro-inflammatory properties, resistin may play a role in the development of NASH in individuals with fatty liver. However, the relationship between serum levels of resistin and NAFLD pathologies remains elusive. O ne study demonstrated that plasma resistin concentrations correlate positively with hepatic fat content [62], but another study demonstrated that these correlations were negative [63]. Furthermore, quantification of the resistin mRNA in subcutaneous adipose tissue led to the conclusion that, in N AFLD, hyper-resistinemia is related to the histological severity of liver disease, but not to IR or body mass index (BM I) [64]. 0 ther researchers report that plasma resistin concentrations are similar in NASH and BMI-matched non-NASH controls $[34,65]$. These contradictory data reflect our current lack of understanding regarding the role of resistin in the pathogenesis of N ASH . C ontinued investigations into the molecular, physiological and clinical studies are needed to determine the role of resistin in the pathogenesis of N AFLD.

\section{Visfatin \& apelin}

Apelin and visfatin are newly discovered hormones secreted by adipose tissue that undergo compensatory upregulation with obesity $[66,67]$. These hormones could theoretically exert beneficial effects through partial alleviation of some of the obesity-related complications [68]. It is important to note that, in addition to visceral and subcutaneous adipose, apelin and visfatin are synthesized elsewhere, particularly skeletal muscle, liver and osteoblasts $[66,68]$. Therefore, these proteins can not be called adipokines in a sensu stricto.

Visfatin is capable of lowering plasma glucose levels, mimicking the effects of insulin on various tissues [69]. For example, visfatin binds to and activates the insulin receptor and stimulates phosphorylation of both IRS-1 and -2, leading to the activation of the downstream Akt and mitogen-activated protein kinases (M APKs) [68,69]. In addition to insulin-like action, visfatin also possesses an enzymatic function that provides nicotinamide mononucleotide (NMN) for a $\mathrm{NAD}^{+}$biosynthetic pathway [70]. Enzymatic function of visfatin as the rate-limiting component in the NAD biosynthesis regulates the transcriptional function of SIRT 1, NAD ${ }^{+}$-dependent deacetylase, which modulates gene silencing, aging and controls the metabolism of WAT. In turn, activated SIRT 1, suppresses PPAR $-\gamma$, the nuclear receptor that promotes adipogenesis; the effect is lipolysis and loss of fat [71]. Therefore, visfatin activity should be antagonistic to thiazolidinediones activity, antidiabetic drugs known to stimulate the adipose mass resulting in weight gain.

It is not known whether increased visfatin production is a simple reflection of the visfatin resistance that could parallel the IR often accompanying morbid obesity, or whether it repre sents an important compensatory pathway. The latter hypothesis is more plausible, as common polymorphisms in the promoter of the visfatin gene pre-B-cell colony-enhancing factor (PBEF)1 influence plasma insulin and glucose levels [72]. The fact that circulating visfatin levels increase along with the deterioration of the pancreatic $\beta$-cells also corroborates the compensatory hypothesis [73]. N evertheless, repeated attempts to correlate serum levels of the visfatin with various clinical parameters of M S have produced contradictory results. Relationships between visfatin levels and diseases of the NAFLD spectrum are unknown.

Apelin, another adipokine, has been associated with peripheral IR because it inhibits glucosestimulated insulin secretion through its receptor apelin-angiotension (APJ), which is expressed in $\beta$-cells of pancreatic islands [74]. Apelin expression in adipocytes is strongly inhibited by fasting and is recovered after re-feeding, and is directly enhanced by insulin [67]. In addition to its pancreatic action, apelin reduces blood pressure by inducing nitric oxide ( $\mathrm{NO}$ )-mediated vasorelaxation and inhibiting water intake [68]. In muscle cells, apelin exerts a selective positive inotropic action and induces contraction [75]. Apelin is also expressed in human osteoblasts and stimulates their proliferation [76].

In mice, apelin expression in fat cells and plasma apelin levels are largely increased in all the hyperinsulinemia-associated obese states, independent of diet composition [67]. Plasma apelin levels are also significantly higher in obese individuals than in normal controls [67,77]. Interestingly, apelin is upregulated by T N F- $\alpha$ in human adipocytes, suggesting another possible link between IR and inflammation [78]. 


\section{Melanocortins \\ $\mathrm{MSH}-\alpha$ \& $\mathrm{MCH}$}

$\mathrm{H}$ istorically, the melanocortin system has been linked to the control of skin and hair pigmentation. Recently, this system has been implicated in the regulation of energy homeostasis and the control of metabolism. A major component of the melanocortin system, $\alpha$-melanocyte-stimulating hormone (M SH ), is produced proteolytically from the pro-opiomelanocortin precursor peptide and serves as a feeding suppressor. Genetic defects inactivating the receptors for $\alpha-\mathrm{MSH}$ have lead to obesity in experimental animals and humans [79]. M elanin-concentrating hormone $(\mathrm{MCH})$, an antagonist of $\alpha-M S H$, is an appetite-stimulating cyclic neuropeptide encoded by the gene PM CH. Both peptides are produced in the hypothalamus and act centrally. In addition, $\alpha-\mathrm{MSH}$ and $\mathrm{MCH}$ peptides are produced in various peripheral tissues, including adipose and exert profound autocrine and paracrine effects. It is likely that the peripheral action of $\alpha-\mathrm{MSH} / \mathrm{M} \mathrm{CH}$ participates in the development of IR and its hepatic manifestation: N AFLD.

Little is known about the signaling events following activation of the $\mathrm{MCH}$ receptors ( $\mathrm{MCH}-\mathrm{R} 1$ or $-\mathrm{R} 2$ ). $\mathrm{MCH}-\mathrm{R} 1$ appears to couple to three different $G \alpha$ subunits, $G \alpha i, G \alpha 0$ and $G \alpha q$, demonstrating the potential for this receptor to activate multiple signaling cascades [80]. D ownstream of $G \alpha$, $\mathrm{M} \mathrm{CH}$ induces activation of p44/42 (extracellular signal-regulated kinase [ERK]1/ERK2) MAPK and pp70 S6 kinase activities [81]. Interest in $\alpha-\mathrm{MSH}$ has been enhanced by the finding that this peptide and its synthetic analogues protect against ischemia/reperfusion injury in various tissues. In myocytes, $\alpha-\mathrm{MSH}$ induces the expression of cytoskeleton proteins and represses immune, inflammatory, cell cycle and protein turnover mediators [82]. Another interesting consequence of $\alpha-\mathrm{M} \mathrm{SH}$ signaling is the suppression of the collagen synthesis and deposition [83]. Furthermore, in fibrotic tissues, $\alpha-\mathrm{MSH}$ treatment modulates the balance between matrix metalloproteinase (MMP)-1, M M P-8 and their inhibitors (TIM PS) [84].

In adipose tissue, $\alpha$-M SH inhibits leptin secretion in differentiated rat adipocytes cultured in vitro. In turn, leptin administered to ob/ob mice increases the release of $\alpha-\mathrm{M} \mathrm{SH}$ into the circulation, suggesting a possible feedback loop between the sites of $\alpha-\mathrm{M}$ SH release and the release of leptin from the adipose tissue [85,86]. The physiological significance of this putative feedback loop probably depends upon the underlying state of energy balance, because low plasma levels of $\alpha-\mathrm{M} \mathrm{SH}$ in fasting animals are paralleled by low plasma leptin [85]. Among other $\alpha-\mathrm{MSH}$-dependent peripheral effects relevant to $\mathrm{MS}$ is the decrease in insulin-secretion by the pancreatic $\beta$-cell [87] and stimulation of lipolysis [88].

Recent studies have focused on the immunosuppressive and anticytokine functions of $\alpha-\mathrm{MSH}$ [89]. Both peripheral blood cells and macrophages residing in human tissues are responsive to $\alpha-M$ SH . In particular, $\alpha-M$ SH downregulates the endotoxin receptor CD 14 present on the macrophages, induces neutrophil elastase, decreases the production of interferon- $\gamma$ by human $T$ cells and modulates immunoglobulin E synthesis by human $B$ cells [89]. In many cell types, $\alpha$-MSH specifically downregulates pro-inflammatory transcription factor nuclear factor (NF)-кB. Furthermore, $\alpha-\mathrm{M} \mathrm{SH}$ inhibits systemic production of $\mathrm{NO}$ and the chemoattractant chemokines, thus modulating inflammatory cell infiltration. Because the same type of the chemokines (e.g., C C L2/M C P-1, C CL 19, IL-6 and IL-8) have been attributed to the progression of simple steatosis to $\mathrm{N} \mathrm{ASH}$, it is reasonable to hypothesize that $\alpha-\mathrm{MSH}$ may play a role in counteracting this progression [90,91]. In addition, broad anticytokine effects of $\alpha-M S H$ suggest that this peptide may also regulate adipokine release, thus producing secondary effects on N AFLD.

Accumulating evidence suggests that $\alpha-\mathrm{MSH}$ mediates liver injury modulation. $\alpha-\mathrm{MSH}$ reduces endotoxin-induced liver inflammation in the mouse model [92], protects against thioacetamide-induced acute liver failure [84] and attenuates carbon tetrachloride $\left(\mathrm{CCl}_{4}\right)$-induced liver fibrosis [93]. The most likely mechanisms for this protection include $\alpha-\mathrm{M} \mathrm{SH}$-dependent inhibition of cell adhesion molecules and cyclooxygenase (COX)-2 expression, as well as the collagenolytic effects exerted through M M P and TIM P modulation [84]. Since hepatic fibrosis may progress in patients with N ASH (as with patients with other chronic liver diseases), the anticollagenic effects of $\alpha-\mathrm{M} \mathrm{SH}$ may be beneficial. In fact, daily or twice daily administration of $\alpha-\mathrm{MSH}$ reduces the symptoms of several other inflammatory diseases in animal models [94]. Additionally, $\alpha-\mathrm{MSH}$ may prolong allograft survival of the experimental heart transplants [82]. Finally, the beneficial effects of $\alpha-\mathrm{M} \mathrm{SH}$ have also been demonstrated in several ischemia/reperfusion models $[92,95,96]$. Together, these findings suggest that $\alpha-\mathrm{M} \mathrm{SH}$ has a potential hepatoprotective effect.

Studies of serum $\alpha$-M SH levels in humans are scarce. O ne study demonstrates that plasma levels of $\alpha-\mathrm{MSH}$ are significantly elevated in obese humans, and that this elevation correlates closely with fat mass $(r=0.586 ; p<0.001)$ and with leptin levels $(r=0.41 ; p<0.05)$ [85]. Another study involving obese and lean females did not reveal any obesity-associated changes in cerebrospinal fluid or plasma $\alpha-\mathrm{MSH}$ levels [97]. Intranasal administration of $\alpha-M S H$ to lean subjects results in distinct reductions of body weight and body fat, which are accompanied by significant decreases in leptin and insulin plasma concentrations [98]. It has been suggested that, unlike normal-weight humans, overweight subjects are not sensitive to the effects of $\alpha-\mathrm{M} \mathrm{SH}$, due to central or peripheral resistance to this peptide [99].

The relationship between plasma levels of $\alpha-\mathrm{MSH}$ and the presence or the progression of other chronic diseases is also unclear. For example, $\alpha$-MSH plasma levels are elevated in patients with congestive heart disease compared with controls [100], whereas $\alpha-\mathrm{M} \mathrm{SH}$ levels are decreased in patients with vitiligo [101]. Plasma $\alpha$-M SH levels are low in samples collected from patients with septic shock at the beginning of septicemia, and gradually increase in patients who recover, but not in those 
who die [102]. It will be interesting to know whether $\alpha-\mathrm{M} \mathrm{SH}$ levels change in NAFLD and NASH, the direction of these changes, and how they reflect the prognosis.

\section{Expert commentary $\&$ five-year view}

The importance of N AFLD as the hepatic manifestation of MS and IR has been increasingly recognized in the past decade. The development of its potentially progressive subtype, NASH , is a complex process that involves multiple mechanisms and is hastened by disturbances of adipocytic secretions (adipokines). The secretion of each adipokine that contributes to NASH depends on both circulating and local concentrations of other bioactive molecules produced in adipose tissue, as well as the macrophage infiltration of adipose tissue. For example, TNF- $\alpha$ potentially reduces the secretion of adiponectin and enhances the expression mRN As encoding pro-inflammatory adipocytokines I L- 6 and -8 [103]. Additionally, T N F- $\alpha$ contributes to obesity-related hyperleptinemia by regulating leptin release from adipocytes [104]. In turn, leptin enhances T N F- $\alpha$ production in lipopolysaccharide (LPS)-stimulated Kupffer cells [105]. T N F- $\alpha$ suppresses production of visfatin and stimulates apelin production $[78,106]$. These and other effects of T N F- $\alpha$ on the accumulation of the fat in the liver and its subsequent inflammation have been thoroughly reviewed [107].

Bioactive molecules released by adipocytes circulate in the serum and interact with corresponding receptors in liver cells and macrophages. These mutually regulating circuits contribute to the vicious pro-inflammatory circle favoring various complications of M S. Larger shifts in the serum content of certain molecules may preferentially drive the development of the particular comorbidities, such as N AFLD.

It is important to note that many of the peripheral signals mentioned in this review are beneficial for homeostasis of the peripheral tissues. Important examples are adiponectin and $\alpha-\mathrm{M} \mathrm{SH}$, which may be capable of alleviating some of the complications of MS. Additionally, $\alpha-M$ SH receptors may represent potential targets for therapeutic intervention in N AFLD . Synthetic agonists of these receptors, melanotans I and II, have already been demonstrated as safe in human trials for therapeutic tanning [108]. A new M TII analogue, PT-141 (Palatin
Technologies, Inc.), which may improve sexual function in both males and females, is scheduled to enter pivotal Stage III clinical trials leading to commercialization [108]. The major difference between these trials and those aimed at the prevention or treatment of N ASH is the necessity for long-term administration of these therapeutic compounds. The consequences of the long-term administration of $\alpha-\mathrm{MSH}$ analogues have not been examined. The potential side effects of prolonged exposure to $\alpha-\mathrm{M} \mathrm{SH}$ include the possibility of developing resistance to its action [99] and increases in bone turnover, which may lead to a net loss of trabecular bone [109]. Both these side effects appear to be relatively mild, so controlled $\alpha-\mathrm{MSH}$ application in patients with diseases within the NASH spectrum may be worth a try.

Adiponectin replenishment is another approach with potential therapeutic application for N ASH . H owever, implementations of these clinical trials are more difficult because adiponectin is a relatively large protein. Furthermore, it has been shown that adiponectin circulates in serum both as a lower molecular weight hexamer and as larger multimeric structures of high molecular weight, which represents its active form [110]. As the formation of high-molecular-weight adiponectin complexes depends on its post-translational hydroxylation and glycosylation [111], it is unlikely that molecular drugs based on recombinant adiponectin will be created anytime soon.

Another breakthrough expected in the field of the adipokine research is the development of novel diagnostic methods based on the multiplexed evaluation of the adipokine and cytokine content of blood serum. Such diagnostics could provide a snapshot of the bioactive serum proteome and reveal the predisposition of an individual to secondary comorbidities within the metabolic spectrum. Early assessment of these predispositions could help clinicians provide patients with individualized recommendation for treatment and necessary lifestyle modifications.

The list of the adipokines and other bioactive molecules influencing the development of metabolic comorbidities is far from complete. A number of interesting molecules with unknown therapeutic potential have recently emerged, including vaspin [112], omentin [113] and others. The interplay between the signaling events produced by bioactive molecules, resistance to

\section{Key issues}

- Metabolic syndrome (MS) is often associated with nonalcoholic fatty liver disease (NAFLD) and its more aggressive form, nonalcoholic steatohepatitis (NASH).

- Adipokines produced by white adipose tissue possess broad physiological activity and play an important autocrine role in obesity-associated complications, including MS, NAFLD and cardiovascular disease.

- Adiponectin and leptin might influence the development of NAFLD and NASH directly.

- Among a plethora of novel soluble molecules regulating or related to fat metabolism, particular attention must be paid to melanocortins. $\alpha$-melanocyte-stimulating hormone and similar anti-inflammatory peptides are safe and have a relatively simple structure, which makes them attractive candidates for future clinical trials.

- A number of well-known (e.g., tumor necrosis factor- $\alpha$ ) and recently discovered (e.g., visfatin and omentin) molecules, are produced by omental adipose. These molecules warrant further investigation as possible participants in the MS milieu. 
insulin and disturbance of lipid metabolism characteristic for morbid obesity, represent an important avenue for future studies on the pathogenesis, diagnosis and treatment of NAFLD and NASH .

\section{Acknowledgement}

Research on melanocortins was partially supported by a research grant from Thomas $F$ and $K$ ate Miller Jeffress Foundation (Ancha Baranova and M anpreet Randhawa).

\section{References}

Papers of special note have been highlighted as:

- of interest

-• of considerable interest

1 Reaven GM . Banting lecture. Role of IR in human disease. D iabetes 37, 1595-1607 (1988).

- Systematic description of the metabolic syndrome.

2 Kahn R, Buse J, Ferrannini E, Stern M. The metabolic syndrome: time for a critical appraisal. Joint statement from the American D iabetes Association and the European Association for the Study of Diabetes. D iabetologi a 48(9), 1684- 1699 (2005).

3 Chitturi S, Farrell GC. Etiopathogenesis of nonalcoholic steatohepatitis. Semin. Liver Dis. 21(1), 27-41 (2001).

- Summary of the multihit hypothesis of nonalcoholic steatohepatitis.

4 M archesini G, M arzocchi R, Agostini F, Bugianesi $E$. N onalcoholic fatty liver disease and the metabolic syndrome. Curr. 0 pin. Lipidol. 16(4), 421-427 (2005).

5 Collantes RS, O ng JP, Younossi ZM. The metabolic syndrome and nonalcoholic fatty liver disease. Panminerva M ed. 48(1), 41-48 (2006).

6 M atteoni CA, Younossi ZM, Gramlich T, Boparai N , Liu YC, M cCullough AJ. $N$ onalcoholic fatty liver disease: a spectrum of clinical and pathological severity. Gastroenterology 116(6), 1413-1419 (1999).

7 Younossi ZM, Diehl AM, Ong JP. $N$ onalcoholic fatty liver disease: an agenda for clinical research. H epatology 35(4), 746- 752 (2002).

8 D ay CP, James O F. Steatohepatitis: a tale of two "hits"? Gastroenterology 114(4), 842-845 (1998).

9 Berg AH, Scherer PE. Adipose tissue, inflammation, and cardiovascular disease. Circ. Res. 96(9), 939-949 (2005).

10 Fain JN. Release of interleukins and other inflammatory cytokines by human adipose tissue is enhanced in obesity and primarily due to the nonfat cells. Vitam. H orm. 74, 443-477 (2006).

- Comparative study of the adipokine and cytokine release by various components of adipose. See also other experimental papers of the same author.
11 Trayhurn P, Wood IS. Signalling role of adipose tissue: adipokines and inflammation in obesity. Biochem. Soc. Trans. 33, 1078-1081 (2005).

12 Dietze $D$, Koenen $M$, Rohrig $K$, $\mathrm{H}$ orikoshi $\mathrm{H}, \mathrm{H}$ auner $\mathrm{H}$, Eckel J. Impairment of insulin signaling in human skeletal muscle cells by co-culture with human adipocytes. D iabetes 51, 2369-2376 (2002).

13 Sell H, D ietze-Schroeder D, Eckel J. The adipocyte- myocyte axis in insulin resistance. Trends Endocrinol. M etab. 17, 416-422 (2006).

14 Sell H, Eckel J, D ietze-Schroeder D. Pathways leading to muscle insulin resistance- the muscle-fat connection. Arch. Physiol. Biochem. 112, 105-113 (2006).

15 Weisberg SP, M cC ann D, D esai M, Rosenbaum M, Leibel RL, Ferrante AW Jr. $O$ besity is associated with macrophage accumulation in adipose tissue. J. Clin. Invest. 112, 1796-1808 (2003).

16 Broglio F, Prodam F, Riganti F, M uccioli G, G higo E. Ghrelin: from somatotrope secretion to new perspectives in the regulation of peripheral metabolic functions. Front. H orm. Res. 35, 102-108 (2006).

- Example of the adipocyte cross-talk between the signaling events originating on different bioactive molecules.

17 O uchi N, Kihara S, Funahashi T, $M$ atsuzawa $Y$, Walsh $K$. O besity, adiponectin and vascular inflammatory disease. Curr. 0 pin. Lipidol. 14(6), 561-566 (2003).

18 M ao X, Kikani CK, Riojas RA et al. APPL 1 binds to adiponectin receptors and mediates adiponectin signalling and function. Nat. Cell. Biol. 8(5), 516-523 (2006).

19 Yamauchi T, Kamon J, M inokoshi Y et al. Adiponectin stimulates glucose utilization and fatty-acid oxidation by activating AM P-activated protein kinase. Nat. M ed. 8(11), 1288-1295 (2002).

20 Chen M B, M cAinch AJ, M acaulay SL et al. Impaired activation of AM P-kinase and fatty acid oxidation by globular adiponectin in cultured human skeletal muscle of obese Type 2 diabetics. J. Clin. Endocrinol. M etab. 90(6), 3665-3672 (2005).
21 Civitarese AE, U kropcova B, Carling S et al. Role of adiponectin in human skeletal muscle bioenergetics. Cell M etab. 4(1), 75-87 (2006).

22 O uchi N, Shibata R, Walsh K. Cardioprotection by adiponectin. Trends Cardiovasc. M ed. 16(5), 141-146 (2006).

23 Diezze-Schroeder D, Sell H, U hlig M , Koenen $M$, Eckel J. Autocrine action of adiponectin on human fat cells prevents the release of insulin resistance-inducing factors. Diabetes 54(7), 2003-2011 (2005).

- Excellent experiments indicating that autocrine action of adiponectin prevent the induction of insulin resistance in peripheral tissues.

24 Fu Y, Luo N, Klein RL, Garvey WT. Adiponectin promotes adipocyte differentiation, insulin sensitivity, and lipid accumulation. J. Lipid Res 46(7), 1369-1379 (2005).

25 Rasmussen M S, Lihn AS, Pedersen SB, Bruun JM , Rasmussen M , Richelsen B. Adiponectin receptors in human adipose tissue: effects of obesity, weight loss, and fat depots. Obesity (Silver Spring) 14(1), 28-35 (2006).

26 Mendez-Sanchez N, Chavez-Tapia NC, Villa AR et al. Adiponectin as a protective factor in hepatic steatosis. World J. Gastroenterol. 11(12), 1737-1741 (2005).

27 Pagano C, Soardo G, Esposito W et al. Plasma adiponectin is decreased in nonalcoholic fatty liver disease. Eur. J. Endocrinol. 152(1), 113-118 (2005).

28 Cesari M, Pessina AC, Zanchetta $M$ et al. Low plasma adiponectin is associated with coronary artery disease but not with hypertension in high-risk nondiabetic patients. J. Intern. M ed. 260(5), 474-483 (2006).

29 Leo R, Di Lorenzo G, Tesauro M et al. $D$ ecreased plasma adiponectin concentration in major depression. N eurosci. Lett. 407(3), 211-213 (2006).

30 Bersinger $\mathrm{NA}$, Birkhauser $\mathrm{MH}$, Wunder D M . Adiponectin as a marker of success in intracytoplasmic sperm injection/embryo transfer cycles. G ynecol. Endocrinol. 22(9), 479-483 (2006).

31 Cust $A E$, Kaaks R, Friedenreich $C$ et al. Plasma adiponectin levels and endometrial cancer risk in pre and post-menopausal women. J. Clin. Endocrinol. M etab. 92(1), 255-263(2006). 
32 Bugianesi $E$, Pagotto $U, M$ anini $R$ et al. Plasma adiponectin in nonalcoholic fatty liver is related to hepatic insulin resistance and hepatic fat content, not to liver disease severity. J. Clin. Endocrinol. M etab. 90, 3498-3504 (2005).

33 Hui JM, H odge A, Farrell GC, Kench JG, Kriketos $A, G$ eorge J. Beyond insulin resistance in N ASH : T N F- $\alpha$ or adiponectin? H epatology 40, 46-54 (2004).

34 M usso G, Gambino R, Biroli G et al. $H$ ypoadiponectinemia predicts the severity of hepatic fibrosis and pancreatic $\beta$-cell dysfunction in nondiabetic nonobese patients with nonal coholic steatohepatitis. Am. J. G astroenterol. 100, 2438-2446 (2005).

35 Kaser S, M oschen A, Cayon A et al. Adiponectin and its receptors in non-alcoholic steatohepatitis. Gut 54, 117-121 (2005).

36 Bjorbaek C, Kahn BB. Leptin signaling in the central nervous system and the periphery. Recent Prog. H orm. Res. 59, 305-331 (2004).

- Excellent overview of the leptin signaling.

37 Nobili V, M anco M, C iampalini $P$ et al. Leptin, free leptin index, insulin resistance and liver fibrosis in children with non-al coholic fatty liver disease. Eur. J. Endocrinol. 155(5), 735-743 (2006).

38 Uygun A, Kadayifci A, Yesilova Z et al. Serum leptin levels in patients with nonalcoholic steatohepatitis. Am. J. Gastroenterol. 95(12), 3584-3589 (2000).

39 Yokoyama H, Hirose H, O hgo H, Saito I. Associations between serum leptin levels and transaminase activities and the status of lifestyle in Japanese workers. Alcohol Clin. Exp. Res. 28(8 Suppl. Proceedings), 159S-163S (2004).

40 Muoio D M, Lynis D ohm G. Peripheral metabolic actions of leptin. Best Pract. Res Clin. Endocrinol. M etab. 16(4), 653-666 (2002).

41 Fishman S, M uzumdar RH , Atzmon G et al. Resistance to leptin action is the major determinant of hepatic triglyceride accumulation in vivo. FASEB J. 21(1), 53-60 (2006).

42 Chitturi S, Farrell G, Frost $L$ et al. Serum leptin in NASH correlates with hepatic steatosis but not fibrosis: a manifestation of lipotoxicity? H epatology 36(2), 403-409 (2002).

43 Shamsuzzaman AS, W innicki M, Wolk R et al. Independent association between plasma leptin and C-reactive protein in healthy humans. Circulation 109(18), 2181-2185 (2004).
44 Aleffi S, Petrai I, Bertolani C et al. U pregulation of proinflammatory and proangiogenic cytokines by leptin in human hepatic stellate cells. H epatology 42(6), 1339-1348 (2005).

45 Ikejima K, O kumura K, Lang T et al. The role of leptin in progression of non-alcoholic fatty liver disease. H epatol. Res. 33(2), 151-154 (2005).

46 Bethanis SK, Theocharis SE. Leptin in the field of hepatic fibrosis: a pivotal or an incidental player? Dig. D is Sci. 51(10), 1685- 1696 (2006).

47 Angulo P, Alba LM, Petrovic LM , Adams $L A$, Lindor $K D$, Jensen $M D$ Leptin, insulin resistance, and liver fibrosis in human nonalcoholic fatty liver disease. J. H epatol. 41(6), 943-949 (2004).

48 Cayon A, Crespo J, M ayorga M, Guerra A, Pons-Romero $F$. Increased expression of $\mathrm{Ob}-\mathrm{Rb}$ and its relationship with the overexpression of T GF- $\beta 1$ and the stage of fibrosis in patients with nonalcoholic steatohepatitis. Liver Int. 26(9), 1065-1071 (2006).

49 Leung JC, Chan LY, Tang SC, Chu KM, Lai KN . Leptin induces TGF- $\beta$ synthesis through functional leptin receptor expressed by human peritoneal mesothelial cell. Kidney Int. 69(11), 2078-2086 (2006).

50 Choudhury J, M irshahi F, M urthy KS, Yager D R, Sanyal AJ. Physiologic concentrations of leptin increase collagen production by non-immortalized human hepatic stellate cells. M etabolism 55(10), 1317-1322 (2006).

51 Wolf $\mathrm{G}$. Insulin resistance and obesity: resistin, a hormone secreted by adipose tissue. N utr. Rev. 62(10), 389-394 (2004).

52 Palanivel R, M aida A, Liu Y, Sweeney G. Regulation of insulin signalling, glucose uptake and metabolism in rat skeletal muscle cells upon prolonged exposure to resistin. D iabetologia 49(1), 183-190 (2006).

53 Fu Y, Luo L, Luo N, Garvey W T. Proinflammatory cytokine production and insulin sensitivity regulated by overexpression of resistin in 3T 3-L 1 adipocytes. N utr. M etab. (Lond.) 3, 28 (2006).

- See also other papers by the same group of authors.

54 Liu T, D hanasekaran SM, Jin $\mathrm{H}$ et al. FIZZ1 stimulation of myofibroblast differentiation. Am. J. Pathol. 164(4), 1315-1326 (2004).
55 Teng X, Li D, Champion HC, Johns RA. $\mathrm{FIZZ1/RELM} \alpha$, a novel hypoxia-induced mitogenic factor in lung with vasoconstrictive and angiogenic properties. Circ. Res. 92(10), 1065-1067 (2003).

56 Thommesen $L$, Stunes AK, M onjo $M$ et al. Expression and regulation of resistin in osteoblasts and osteoclasts indicate a role in bone metabolism. J. Cell. Biochem. 99(3), 824-834 (2006).

57 Yang RZ, H uang Q, Xu A et al. Comparative studies of resistin expression and phylogenomics in human and mouse. Bi ochem. Biophys. Res. Commun. 310(3), 927-935 (2003).

- Review of the human and rodent resistin families with emphasis on their differences.

58 O rt T, Arjona AA, M acD ougall JR et al. Recombinant human $\mathrm{FIZZ3/resistin}$ stimulates lipolysis in cultured human adipocytes, mouse adipose explants, and normal mice. Endocrinology 146(5), 2200-2209 (2005).

-. Experimental proofs that human and murine resistins act upon adipocytes differently.

59 Kusminski CM , M cTernan PG, Kumar S. Role of resistin in obesity, insulin resistance and Type II diabetes. Clin. Sci. (Lond.) 109(3), 243-256 (2005).

60 Fehmann H C, H eyn J. Plasma resistin levels in patients with type 1 and type 2 diabetes mellitus and in healthy controls. H orm. M etab. Res 34(11-12), 671-373 (2002).

61 Lee JH, Chan JL, Yiannakouris N et al. Circulating resistin levels are not associated with obesity or insulin resistance in humans and are not regulated by fasting or leptin administration: cross-sectional and interventional studies in normal, insulin-resistant, and diabetic subjects. J. Clin. Endocrinol. M etab. 88(10), 4848-4856 (2003).

62 Bajaj M, Suraamornkul S, H ardies LJ, Pratipanawatr T, D efronzo RA.

Plasma resistin concentration, hepatic fat content, and hepatic and peripheral insulin resistance in pioglitazone-treated type II diabetic patients. Int. J. O bes. Relat M etab. Disord. 28(6), 783-789 (2004).

63 Perseghin G, Lattuada G, D e Cobelli F et al. Serum resistin and intra-hepatic fat content in non-diabetic individuals J. Clin. Endocrinol. M etab. (2006).

64 Pagano C, Soardo G, Pilon C et al. Increased serum resistin in nonalcoholic fatty liver disease is related to liver disease severity and not to insulin resistance. J. Clin. Endocrinol. M etab. 91(3), 1081-1086 91(3), 1081-1086 (2006). 
65 Baranova A, G owder SJ, Schlauch K et al. $G$ ene expression of leptin, resistin, and adiponectin in the white adipose tissue of obese patients with non-alcoholic fatty liver disease and insulin resistance. 0 bes. Surg. 16(9), 1118-1125 (2006).

66 Berndt J, K loting N , Kralisch S et al. Plasma visfatin concentrations and fat depot-specific mRN A expression in humans. Diabetes 54(10), 2911-2916 (2005).

67 Boucher J, M asri B, D aviaud D et al. Apelin, a newly identified adipokine up-regulated by insulin and obesity. Endocrinology 146(4), 1764-1771 (2005).

68 Beltowski J. Apelin and visfatin: unique "beneficial" adipokines upregulated in obesity? M ed. Sci. M onit. 12(6), RA112-RE119 (2006).

69 Fukuhara A, M atsuda M, N ishizawa M et al. Visfatin: a protein secreted by visceral fat that mimics the effects of insulin. Science 307(5708), 426-30(2005).

- Study of the insulin-mimetic effects of visfatin.

70 Wang $T$, Zhang X, Bheda P, R evollo JR, Imai $S$, W olberger $C$. Structure of $\mathrm{N}$ ampt/PBEF/visfatin, a mammalian $\mathrm{NAD}+$ biosynthetic enzyme. $\mathrm{N}$ at. Struct. Mol. Biol. 13(7), 661-662 (2006).

71 Wolf G. Calorie restriction increases life span: a molecular mechanism. N utr. Rev. 64(2 Pt 1), 89-92 (2006).

72 Bailey SD, Loredo-O sti JC, Lepage P et al. Common polymorphisms in the promoter of the visfatin gene (PBEF 1 ) influence plasma insulin levels in a French-C anadian population. Diabetes 55(10), 2896-2902 (2006).

73 Lopez-Bermejo A, Chico-Julia B, Fernandez-Balsells $M$ et al. Serum visfatin increases with progressive $\beta$-cell deterioration. D iabetes 55(10), 2871-2875 (2006).

74 Sorhede W inzell M, M agnusson C, Ahren $B$. The APJ receptor is expressed in pancreatic islets and its ligand, apelin, inhibits insulin secretion in mice. Regul. Pept. 131(1-3), 12-17 (2005).

75 Szokodi I, Tavi P, Foldes G et al. Apelin, the novel endogenous ligand of the orphan receptor APJ, regulates cardiac contractility. Circ. Res. 91(5), 434-440 (2002).

76 XieH, Tang SY, Cui RR et al. Apelin and its receptor are expressed in human osteoblasts. Regul. Pept. 134(2-3), 118-125 (2006).

77 H einonen $M V$, Purhonen AK, M iettinen $P$ et al. Apelin, orexin-A and leptin plasma levels in morbid obesity and effect of gastric banding. Regul. Pept. 130(1-2), 7-13 (2005).
78 D aviaud D, Boucher J, G esta S et al. $T N F \propto$ up-regulates apelin expression in human and mouse adipose tissue. FASE B J. 20(9), 1528-1530 (2006)

79 Farooqi IS, Keogh JM, Yeo GS, Lank EJ, Cheetham T, O 'Rahilly S. Clinical spectrum of obesity and mutations in the melanocortin 4 receptor gene. $\mathrm{N}$. Engl. J . M ed. 348(12), 1085-1095 (2003).

80 Eberle AN, Mild G, Schlumberger $S$, D rozdz R, H intermann $E$, Zumsteg $U$. Expression and characterization of melanin-concentrating hormone receptors on mammalian cell lines. Peptides 25(10), 1585-1595 (2004).

81 Bradley RL, M ansfield JP, M aratos-Flier E, C heatham B. M elanin-concentrating hormone activates signaling pathways in 3T 3-L1 adipocytes. Am. J. Physiol. Endocrinol. M etab. 283(3), E584-E592 (2002).

82 Colombo G, Gatti S, Turcatti F et al. $G$ ene expression profiling reveals multiple protective influences of the peptide $\alpha$ melanocyte-stimulating hormone in experimental heart transplantation. J. Immunol. 175, 3391-3401 (2005).

83 Bohm M, Raghunath $M$, Sunderkotter C et al. Collagen metabolism is a novel target of the neuropeptide $\alpha$-melanocytestimulating hormone. J. Biol. Chem. 279(8), 6959-6966 (2004).

84 Wang $\mathrm{CH}$, Jawan $\mathrm{B}$, Lee TH et al. Single injection of naked plasmid encoding $\alpha$-melanocyte-stimulating hormone protects against thioacetamide-induced acuteliver failurein mice. Biochem. Biophys. Res. Commun. 322, 153-161 (2004).

$85 \mathrm{H}$ oggard N, H unter L, D uncan J S, Rayner DV. Regulation of adipose tissue leptin secretion by $\alpha$-melanocytestimulating hormone and agouti-related protein: further evidence of an interaction between leptin and the melanocortin signalling system. J. M ol. Endocrinol. 32(1), 145-153 (2004).

86 Norman $D$, Isidori $A M$, Frajese $V$ et al. ACTH and $\alpha-M S H$ inhibit leptin expression and secretion in 3T 3-L1 adipocytes: model for a central-peripheral melanocortin-leptin pathway. M ol. Cell Endocrinol. 200(1-2), 99-109 (2003).

87 Shimizu H, Tanaka Y, Sato N, M ori M. $\alpha$-melanocyte-stimulating hormone(M SH ) inhibits insulin secretion in H IT-T 15 cells. Peptides 16(4), 605-608 (1995).

88 Cho KJ, Shim JH, Cho M C et al. Signaling pathways implicated in $\alpha$-melanocytestimulating hormone-induced lipolysis in 3T 3-L 1 adipocytes. J. Cell Biochem. 96(4), 869-878 (2005).
$89 \mathrm{M}$ aaser $\mathrm{C}, \mathrm{K}$ annengiesser $\mathrm{K}$, Kucharzik $\mathrm{T}$. Role of the melanocortin system in inflammation. Ann. NY Acad. Sci. 1072, 123-134 (2006).

90 H aukeland JW, D amas JK, Konopski Z et al. Systemic inflammation in nonal coholic fatty liver disease is characterized by elevated levels of C CL2. J. H epatol. 44(6), 1167-1174 (2006).

91 Bahcecioglu IH, Yalniz M , Ataseven $\mathrm{H}$ et al. Levels of serum hyaluronic acid, TN F- $\alpha$ and IL-8 in patients with nonalcoholic steatohepatitis. H epatogastroenterology 52(65), 1549-1553 (2005).

92 Chiao H, Kohda Y, M cLeroy P, Craig L, H ousini I, Star RA. $\alpha$-melanocytestimulating hormone protects against renal injury after ischemia in mice and rats. J. Clin. Invest. 99(6), 1165-1172 (1997).

93 Lee TH, Jawan B, Chou WY et al. $\alpha$-melanocyte-stimulating hormone gene therapy reverses carbon tetrachloride induced liver fibrosis in mice. J. Gene M ed. 8(6), 764-772 (2006).

94 Rajora N, Boccoli G, Catania A, Lipton JM . $\alpha$-M SH modulates experimental inflammatory bowel disease. Peptides 18(3), 381-385 (1997).

$95 \mathrm{H}$ uang $\mathrm{Q}$, Tatro JB. $\alpha$-melanocyte stimulating hormone suppresses intracerebral tumor necrosis factor- $\alpha$ and interleukin-1 $\beta$ gene expression following transient cerebral ischemia in mice. Neurosci. Lett. 16, 334(3), 186-190 (2002).

96 D eng J, $\mathrm{H}$ u X, Yuen PS, Star RA. $\alpha$-melanocyte-stimulating hormone inhibits lung injury after renal ischemia/reperfusion. Am. J. Respir. Crit. Care M ed. 169(6), 749-756 (2004).

$97 \mathrm{~N}$ am SY, Kratzsch J, Kim KW, Kim KR, Lim SK, M arcus C. C erebrospinal fluid and plasma concentrations of leptin, N PY, and $\alpha$-M SH in obese women and their relationship to negative energy balance. J. Clin. Endocrinol. M etab. 86(10), 4849-4853 (2001).

98 Fehm H L, Smolnik R, Kern W, M cGregor GP, Bickel U, Born J. The melanocortin melanocyte-stimulating hormone/adrenocorticotropin (4-10) decreases body fat in humans. J. Clin. Endocrinol. M etab. 86(3), 1144-1148 (2001).

99 H allschmid M, Smolnik R, M CG regor G, Born J, Fehm HL. O verweight humans are resistant to the weight-reducing effects of melanocortin4-10. J. Clin. Endocrinol. M etab. 91(2), 522-525 (2006). 
100 Yamaoka-Tojo M, Tojo T, Shioi T, $M$ asuda $T$, Inomata $T$, Izumi $T$. Central neurotranspeptide, $\alpha$-melanocytestimulating hormone ( $\alpha-\mathrm{MSH}$ ) is upregulated in patients with congestive heart failure. Intern. M ed. 45(7), 429-434 (2006).

101 Pichler R, Sfetsos K, Badics B, Gutenbrunner S, Aubock J. Vitiligo patients present lower plasma levels of $\alpha$-melanotropin immunoreactivities. NeuroPeptides 40(3), 177-183 (2006).

102 Catania A, Cutuli M, Garofalo L et al. Plasma concentrations and anti-L-cytokine effects of $\alpha$-melanocyte stimulating hormone in septic patients. Crit. Care M ed. 28(5), 1403-1407 (2000)

-. See also other publications of the same author.

103 Kim KY, Kim JK, Jeon JH, Yoon SR, Choi I, Yang Y. c-Jun $\mathrm{N}$-terminal kinase is involved in the suppression of adiponectin expression by T N F- $\alpha$ in 3T 3-L1 adipocytes. Biochem. Biophys. Res. Commun. 327(2), 460-467 (2005).

104 Kirchgessner TG, Uysal KT, W iesbrock SM , $M$ arino $M$ W, $H$ otamisligil $G S$. Tumor necrosis factor- $\alpha$ contributes to obesity-related hyperleptinemia by regulating leptin release from adipocytes. J. Clin. Invest. 100(11), 2777-2782 (1997).

105 Shen J, Sakaida I, U chida K, Terai S, Okita K. Leptin enhances T N F- $\alpha$ production via p38 and J N K M APK in LPS-stimulated K upffer cells. Life Sci. 77(13), 1502-1515 (2005).
106 K ralisch S, K lein J, L ossner U et al. $\mathrm{H}$ ormonal regulation of the novel adipocytokine visfatin in 3T 3-L 1 adipocytes. J. Endocrinol. 85, R1-R8 (2005).

107 D iehl AM. Tumor necrosis factor and its potential role in insulin resistance and nonalcoholic fatty liver disease. Clin. Liver D is. 8(3), 619-38 (2004).

$108 \mathrm{H}$ adley M E, Dorr RT. M elanocortin peptide therapeutics: historical milestones, clinical studies and commercialization. Peptides 27(4), 921-930 (2006).

109 Cornish J, Callon KE, M ountjoy KG et al. $\alpha$-melanocyte-stimulating hormone is a novel regulator of bone. Am. J. Physiol. Endocrinol. M etab. 284(6), E1181-E1190 (2003).

110 Fisher FF, Trujillo ME, H anif W et al. Serum high molecular weight complex of adiponectin correlates better with glucose tolerance than total serum adiponectin in Indo-Asian males. Diabetologia 48(6), 1084-1087 (2005)

111 Wang Y, Lam KS, Chan L et al. Post-translational modifications of the four conserved lysine residues within the collagenous domain of adiponectin are required for the formation of its high molecular weight oligomeric complex. J. Biol. Chem. 281(24), 16391-16400 (2006).

112 Hida K, Wada J, Eguchi J et al. Visceral adipose tissue-derived serine protease inhibitor: a unique insulin-sensitizing adipocytokine in obesity. Proc. $\mathrm{N}$ atl Acad. Sci. U SA 102(30), 10610-10615 (2005).
113 Yang RZ, Le M J, Hu H et al. Identification of omentin as a novel depot-specific adipokine in human adipose tissue: possible role in modulating insulin action. Am. J. Physiol. Endocrinol. M etab. 290(6), E1253-E 1261 (2006).

\section{Affiliations}

- Ancha Baranova, PhD, DSci Center for Liver D iseases, Inova Fairfax H ospital, VA, USA

Tel.: +1 7039934292

Fax: +1 7039934393

abaranov@gmu.edu

- M anpreet Randhawa, MS George M ason University, Center for the Study of Genomics in Liver D iseases, M olecular \& M icrobiology D epartment, VA, USA Tel.: +1 7039938512 Fax: +1 7039934393 mrandha1@gmu.edu

- M ohammed Jarrar, MS George M ason University, Center for the Study of $G$ enomics in Liver Diseases, M olecular $\&$ M icrobiology D epartment, VA, U SA Tel.: +1 7039938512 Fax: +1 7039934393 mjarrar@gmu.edu

- Zobair M Younossi, MD, M PH Inova Fairfax H ospital, Center for Liver D iseases, D epartment of M edicine, 3300 Gallows Road, VA22042, U SA Tel.: +1 703698 3182; +1 7032086650

Fax: +1 703698 3482; +1 7032086655 zobair.younoss@inova.com 
Reproduced with permission of the copyright owner. Further reproduction prohibited without permission. 